\title{
A revolução científica: um olhar sociológico sobre a história da ciência
}

\author{
Scientific revolution: a sociological look at the \\ bistory of sciences
}

\author{
Ricardo Roque \\ Universidade dos Açores \\ roque@notes.uac.pt
}

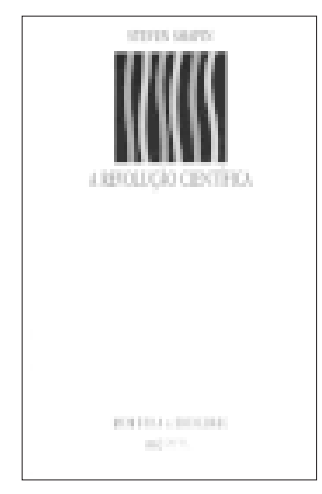

Steven Shapin, A revolução científica Trad. Ricardo Roque, Lisboa, Difel, Colecção Memória e Sociedade, 1999.

\begin{abstract}
"A imagens tradicionais da ciência estão a ser atacadas." Esta frase ousada bem poderia descrever o ímpeto revolucionário dos filósofos naturais do século XVII, analisados por Steven Shapin em $A$ revolução científica, obra de 1996 recentemente surgida em tradução para a língua portuguesa. Mas não. Quem a proferiu foi um nosso contemporâneo, o sociólogo Donald Mackenzie (1981, p. ix), ao introduzir o seu trabalho sobre a emergência das teorias estatísticas na viragem para o século XX. ${ }^{1}$ Com essa expressão, Mackenzie estava a captar o ataque aos modos "tradicionais" de fazer história e sociologia da ciência lançado desde meados da década de 1970 pela auto-intitulada sociology of scientific knowledge (mais conhecida por SSK), em particular pelo grupo reunido na Science Studies Unit da Universidade de Edimburgo, na Escócia. Shapin, então companheiro de Mackenzie em Edimburgo, iniciava a sua carreira intelectual na crista desse ataque revisionista. Apresentar Steven Shapin como autor implica, pois, vê-lo como actor deste esforço para reformar os estudos sociais da ciência. Um esforço que compreende igualmente $A$ revolução científica, trabalho de síntese que possibilita numa narrativa acessível um encontro com o programa sociológico que Shapin lançou como impulso de reforma da história da ciência.

Sabemos, face a obras como esta sobre a "revolução científica", que não existem, de facto, revoluções abruptas e dramáticas no conhecimento. Mas sabemos igualmente, como demonstra ainda este ensaio de Shapin, que isso não nos impede de falar de processos de mudança, ou de analisar o trabalho dos actores com vista a rever certas formas de conhecimento, nem nada impede que esses esforços provoquem de facto certas modificações. Não se trata aqui de julgar o alcance das descontinuidades introduzidas pelo assalto à relação entre a ciência e o seu contexto social encetado desde meados da década de 1970, e no qual Shapin foi um dos actores principais. Delegue-se essa tarefa, e esse desafio, a quem quiser lançar-se hoje numa sociologia do conhecimento científico. Trata-se de eleger esse processo de crítica
\end{abstract}

\footnotetext{
${ }^{1}$ Para uma imagem geral e introdutória ao desenvolvimento da sociologia do conhecimento científico no Reino Unido na década de 1980, ver Collins (1983), bem como a revisão do próprio Shapin (1985).
} 
e revisão dos estudos da ciência como contexto escolhido e construído por Steven Shapin para dar abrigo às suas investigações. Neste breve texto, pretendo dar ao leitor de $A$ revolução científica algumas coordenadas que o familiarizem com esse contexto e situem o percurso intelectual de um autor cujo contributo é agora incontornável para perceber os recentes desenvolvimentos da história e sociologia do conhecimento científico. Espero poder assim secundá-lo na leitura desta obra.

Shapin é actualmente professor de sociologia na Universidade da Califórnia, San Diego, instituição onde lecciona desde meados da década de 1980. Concluiu os seus estudos em biologia e genética no Read College e na Universidade de Wisconsin, nos Estados Unidos, doutorando-se em 1971 em história e sociologia da ciência na Universidade da Pensilvânia. Foi então que seguiu para a Universidade de Edimburgo, na Escócia, onde ensinou história da ciência na Science Studies Unit até a década de 1980. Desenvolveu aí uma fértil colaboração com o sociólogo Barry Barnes, expressa em várias publicações conjuntas (p. ex., Shapin e Barnes, 1977; Barnes e Shapin, 1979), e investigou a ciência natural na Escócia dos séculos XVIII e XIX. Foi perante este objecto de estudo que Shapin, formado nos Estados Unidos e treinado na então canónica sociologia da ciência mertoniana, primeiro confrontou o problema da relação entre a ciência e o contexto social.

Esta era justamente a questão fundadora da análise sociológica da ciência desde os trabalhos seminais de Robert K. Merton $(1973,1970)$ na década de 1930. Pelo menos desde a Segunda Guerra Mundial que qualquer praticante que pretendesse afirmar-se no estudo da ciência e da mudança científica deveria definir a sua posição face às duas abordagens que dividiam o género: o "externalismo" e o "internalismo". Em termos gerais, os representantes da primeira abordagem procuravam explicar a natureza e a mudança no conhecimento científico aludindo a "factores sociais", externos ao conhecimento propriamente dito. Estes factores eram vistos como uma influência que actuava do exterior da ciência, a sociedade, para o seu interior, o conhecimento científico propriamente dito. Na prática, correspondiam às instituições e aos cientistas, actuando sob a forma, por exemplo, de "interesses", "estrutura social", ou "comunidade científica", esta última a fórmula eleita por Thomas Kuhn para desenvolver a sua leitura sociológica da ciência. A autoridade da sociologia mertoniana dependia em particular da sua capacidade para demonstrar a intromissão desses factores na dinâmica científica, sem contudo deixar de reservar para a ciência um domínio interno, puro e intrínseco — o do próprio conhecimento. Segundo Shapin (1988), a sociologia de Merton supunha a existência de fronteiras claras e autocontidas entre a ciência e a sociedade, à imagem dos sistemas sociais de Pitirim Sorokin, de tal modo que os conteúdos cognitivos da ciência não se prestavam a uma análise sociológica. Por seu turno, os estudos "internalistas", representados grosso modo pela filosofia das ciências e a história das idéias e cujo representante mais emblemático foi talvez Alexandre Koyré, ocupavam-se exclusivamente dos conteúdos cognitivos da ciência. A mudança científica explicava-se apelando a uma espécie de força causal intrínseca às ideias. 
Neste debate, a divisão ontológica entre ciência e sociedade significava ao mesmo tempo um recurso explicativo e uma instituição cuja ruptura de fronteiras contaminaria a qualidade dos conteúdos científicos - daí a feroz desconfiança com que os dois lados do debate olhavam a abordagem marxista das décadas de 1940 e 1950, acusada de desvirtuar a ciência ao reduzir a explicação dos seus processos à acção de meros factores sociais. Quem se atrevesse a sugerir que o conteúdo cognitivo da ciência era passível de uma compreensão puramente sociológica corria o risco de ver-se acusado de profanador de templos. Foi precisamente contra essa divisão ontológica, organizadora dos modelos explicativos do "internalismo" e do "externalismo", que Shapin e os revisionistas das décadas de 1970 e 1980 se tentaram afirmar. Na década de 1990, esta mesma investida parece permanecer central na identidade da sociologia do conhecimento científico. De facto, tudo leva a crer que esses modelos, apesar de criticados à exaustão, continuem a marcar muito do que se escreve e diz acerca da ciência, seja na linguagem comum, seja na própria produção especializada. Compreende-se assim que Shapin (1992) continue reclamando a reavaliação desse debate que muitos declararam como morto. E o certo é que em $A$ revolução científica, volta a apontar as baterias para as tradicionais narrativas internalistas sobre a mudança científica e para a instituição que aparta a ciência da sociedade — desta feita, com a consequência, creio, de estilhaçar as noções tradicionais sobre a mudança científica, ao repor, a partir das práticas, a incerteza, contingência e heterogeneidade dos processos históricos.

Na década de 1970, inconformado com o debate tradicional, Shapin (1992, pp. 342-5) começou por tentar fazer a ponte entre os dois pólos da questão. Tratava-se de procurar reunir numa mesma explicação elementos internos (cognitivos) e externos (sociais) evitando cair em extremismo. ${ }^{2}$ Todavia, esta espécie de compromisso - a que mais tarde chamou de posição "ecléctica" - continuava a mover-se num quadro tradicional, ora privilegiando o estudo dos cientistas, ora procurando evidenciar influências sociais extrínsecas nos conteúdos cognitivos, o que mantinha intocável a separação entre crença e estrutura social. Estudou deste modo as "audiências externas" da ciência escocesa e, depois, como Mackenzie, recorreu à noção de "interesses sociais" para demonstrar como a avaliação de factos científicos na frenologia oitocentista tanto implicou "puros" interesses científicos quanto interesses profissionais e de classe (Shapin, 1979, 1975, 1974). Mas seria através das controvérsias científicas que o olhar sociológico de Shapin se mostraria mais acutilante sobre a história da ciência tradicional. O interesse pela pesquisa das controvérsias entre cientistas era então um dos novos focos empíricos reclamados pelos protagonistas da SSK, pois permitia evidenciar o carácter relativo, incerto e contingente do estabelecimento da "verdade" acerca do mundo natural. A SSK tomou-o como uma das suas bandeiras. Assim se compreende que, na década de 1980, sem perder de vista o assalto à fractura tradicional, Shapin (1981) se mostrasse sensível ao dinamismo histórico das polémicas. Ao

\footnotetext{
${ }^{2}$ Procurou fazê-lo, por exemplo, através da análise prosopográfica dos cientistas (Shapin e Thackray, 1974).
} 
mesmo tempo, interessava-se pelas origens da ciência moderna no século XVII, concentrando-se na investigação do experimentalismo de Robert Boyle e da Royal Society of London. Desse interesse resultaria o extenso estudo, já clássico, sobre a controvérsia seiscentista entre Thomas Hobbes e Robert Boyle, Leviathan and the air-pump, produzido em co-autoria com Simon Schaffer (1985). ${ }^{3}$

Este trabalho traduz na verdade uma importante reorientação na sua abordagem da dicotomia entre o social e o científico, que, afinal, como demonstraram Shapin e Schaffer (1985, p. 342), constitui um dos pilares da modernidade ocidental. A separação ontológica entre a "natureza" dos objectos (cujo representante e porta-voz tomamos como a "ciência") e a "sociedade" dos sujeitos (representada pelo domínio da "política") transformou-se em questão de investigação. "A linguagem que transporta a política para fora da ciência", escreviam em desafio, "é aquilo que precisamos de compreender e explicar." Tomando o desacordo entre Boyle e Hobbes (autores que nos habituámos a arrumar como fundadores respectivamente da ciência e da política modernas), Shapin e Schaffer puseram em prática uma arqueologia da separação entre a ciência e a sociedade, detectando que fora essa mesma divisão que os filósofos experimentalistas do século XVII se esforçaram por estabelecer como legítima condição de possibilidade para a sua prática. De categorias explicativas dadas por adquiridas, os dois pólos da divisão converteram-se em tópicos problemáticos, as categorias a explicar pelo estudo empírico da sua constituição histórica. Nesta arqueologia, não se tratava de usar a "sociedade" e o "social" como causa para explicar o que acontecia no domínio da "natureza", movimento característico da postura sociológica corrente perante o conhecimento natural. Colocadas no seu contexto histórico de emergência, essas entidades surgiam como efeitos históricos incertos e contingentes de um processo colectivo de discussão e negociação entre os actores. Da perspectiva de Shapin (1992), esta arqueologia das categorias, movimento de reflexividade suportado num historicismo moderado, define, na verdade, um programa alternativo para os estudos históricos da ciência enfrentarem as ontologias modernas. Alternativo em particular a outro importante projecto de reforma dos estudos da ciência em relação ao qual Shapin se mantém crítico, justamente as abordagens que abriram espaço à noção de "actor-rede" inicialmente desenvolvida por Michel Callon, John Law e Bruno Latour. ${ }^{4}$

Mais do que na enunciação de princípios, foi com o próprio exercício de análise da controvérsia que Shapin e Schaffer interpelaram a tradicional imunidade sociológica usufruída pelos conteúdos cognitivos da ciência. Aliás, Shapin evitou a formalização como estratégia para afirmar o seu programa sociológico. Em vez de, por exemplo, escrever tratados teóricos e metodológicos à maneira dos epistemólogos tradicionais, procurou introduzir

\footnotetext{
3 Ver como, no quadro da sua "antropologia dos modernos", Bruno Latour (1991) comentou criticamente a importância deste trabalho na renovação do olhar sociológico no estudo da ciência e da modernidade.

${ }^{4}$ Uma fonte sintética desta teoria, bem como um útil guia bibliográfico nos novos estudos da ciência e da tecnologia, é Latour (1995). Para desenvolvimentos recentes, ver Law e Hassard (1999).
} 
a possibilidade da mudança através do modo como fazia sociologia. Apresentou-se então como praticante de uma espécie de epistemologia empírica, investigando episódios históricos específicos com o apoio de um largo conjunto de fontes: "(a) melhor maneira de estabelecer a possibilidade de fazer uma coisa é fazendo-a" (Barnes e Shapin, 1979, p. 11).

Assim, Shapin e Schaffer (1985) empreenderam a mudança ao pôr a funcionar na análise do debate entre Hobbes e Boyle a sua célebre proposição de que "soluções para problemas de conhecimento são soluções para problemas de ordem social". Fizeram-no de modo simétrico: leram o experimentalismo de Boyle como programa social e o Leviathan de Hobbes como programa epistemológico, convertendo ambos em programas simultaneamente políticos, sociais e científicos. Demonstraram assim como os dois lados da controvérsia apresentavam diferentes soluções quanto à melhor maneira de produzir e garantir um conhecimento natural, soluções essas que eram ao mesmo tempo formas de resolver os problemas de ordem política e religiosa vividos pela sociedade inglesa do século XVII, afectada pela crise da Restauração. Deram também atenção aos aspectos tecnológicos tornando-os constitutivos dos conteúdos cognitivos. Acertavam assim noutra dicotomia tradicional (ciência/tecnologia): 5 Shapin e Schaffer acentuaram a importância de olhar para os modos como era feito o conhecimento, conferindo uma centralidade pioneira à actividade dos dispositivos materiais (como a bomba de ar de Boyle) na constituição e expansão, sempre problemáticas, do conhecimento mecanicista.

Mas o movimento de Shapin não se compreende apenas como reacção negativa ao debate tradicional. É necessário trazer para aqui o contexto positivo que mobiliza, sem com isso pretender, evidentemente, estabelecer linhagens ou esgotar a rede de intervenientes na sua prática de conhecimento. Marcam desde logo presença o impulso relativista de Thomas Kuhn (1970) na história e sociologia da ciência e os desenvolvimentos dos parceiros de Shapin na empresa revisionista - além de Barnes, Mackenzie, David Bloor e Andrew Pickering, seus companheiros em Edimburgo, e do próprio Simon Schaffer, apontem-se também Harry M. Collins, Trevor J. Pinch, Bruno Latour, entre outros. Excepção talvez feita a Latour, de obra mais difusa, estes últimos autores realizaram estudos etnográficos ou "microssociológicos" em cenário laboratorial, assim proporcionando a Shapin um importante repertório para entender a experimentação e a construção de factos como prática local e contingente, tão trivial como qualquer outra prática quotidiana. Shapin vem insistindo assim na importância de ver a ciência como uma prática produzida por actores humanos em situações históricas específicas.

Referência importante é também a antropologia tout court, que Shapin combina com uma abordagem histórica, assim como a teoria social do conhecimento de Wittgenstein, então sujeita a escrutínio pelos novos estudiosos da ciência (Bloor, 1983). Foi com base na noção wittgensteiniana de que o acto discursivo, o "jogo da linguagem",

\footnotetext{
${ }^{5}$ Esta separação estava na mira dos novos estudos da tecnologia. Ver, por exemplo, Pinch e Bijker (1984)
} 
é uma actividade prática ou uma "forma de vida", que Shapin e Schaffer partiram para dissolver a distinção ontológica entre, por um lado, contexto e formas sociais e, por outro, discurso e conteúdos cognitivos. Desde a década de 1970 que, apesar de ligado às categorias mertonianas, procurava uma "epistemologia social" que resolvesse o binómio social/científico. Enquanto se ancorava mais a fundo em Wittgenstein, Shapin socorreu-se também das perspectivas antropológicas, em especial do trabalho de Mary Douglas (1978, 1970) sobre a instituição das noções de pureza e poluição, bem como as suas investigações sobre o isomorfismo entre natural e social nas cosmologias das culturas pré-letradas. Investiu, então, numa análise do conhecimento tal como emerge nos seus contextos de uso, apoiado numa perspectiva simétrica. Na verdade, este ponto de vista sugeriulhe uma descrição do conhecimento científico e "racional" como se este tratasse de qualquer cosmologia "irracional" não ocidental, na qual as homologias entre os domínios do natural e do social não se apresentavam travadas pelas fronteiras entre natureza e sociedade próprias à cultura moderna do Ocidente.

A antropologia proporcionou igualmente um modelo metodológico. Foi tentando vestir a pele do viajante em terras estranhas à imagem do antropólogo que Shapin e Schaffer se aventuraram na sua aproximação ao familiar programa experimental de Boyle, hoje identificado com a ciência moderna. A sensibilidade de "estrangeiro" é completada pela tentativa de produzir um estudo "descritivo e explicativo" dos seus objectos, despido de juízos "avaliativos" (Shapin e Schaffer, 1985, pp. 12-3). Este esforço para tornar estranho o que é familiar encontrava também eco na nova sociologia, que se orientava para posições de relativa imparcialidade e agnosticismo face aos objectos de estudo e aos seus usos sociais, atitude que poderá ser em parte interpretada como reacção ao comprometimento dos sociólogos da ciência das décadas de 1950 e 1960 com o planeamento científico e as suas consequências sociais. Ainda que Shapin (1992, pp. 357-60) se venha mostrando mais céptico quanto à possibilidade efectiva de atingir essa neutralidade e pureza acadêmica, cujo custo, reconhece, seria o isolamento do sociólogo da ciência face ao resto do mundo, é inegável a importância deste duplo posicionamento, simétrico e imparcial, no seu trabalho, bem como na afirmação dos novos estudos da ciência. Bastará referir o emblema mais radical do novo relativismo, precisamente o strong programme avançado na década de 1970 por David Bloor (1976), argumentando que o sociólogo do conhecimento científico devia agir de forma simétrica e imparcial, independentemente das verdades e da racionalidade que professava.

Estes contextos permanecem importantes nos trabalhos de Steven Shapin desde finais da década de 1980. Continuando a explorar as origens da ciência moderna a partir do programa experimentalista de Boyle, o trabalho de Shapin vem aprofundando o filão aberto com Leviathan and the air-pump. Mantém-se interessado em desmontar historicamente as categorias que marcam o modo como hoje entendemos a ciência moderna. Neste sentido, vem-se interessando, por um lado, em localizar o conhecimento e a experimentação no 
espaço, ao investigar os lugares seiscentistas de produção dos factos experimentais (Shapin, 1990, 1988). Por outro, num reencontro crítico com o foco sociológico nos cientistas, tem investido no modo como se constituiu e legitimou a comunidade científica no século XVII e, em particular, a identidade do filósofo experimental moderno a partir da Royal Society of London (idem, 1993, 1991). É deste modo que Shapin procura rever as teses clássicas de Weber e Merton que identificavam o puritanismo como a principal fonte de legitimidade da prática científica moderna. Do seu ponto de vista particular, Shapin tenta problematizar essa tese virando-a para os códigos de conduta e moral dos gentlemen ingleses do século XVII. Sugere igualmente como, neste contexto histórico, estes mesmos códigos poderão permitir entender, à revelia do tradicional discurso sobre o método científico, o padrão normativo da avaliação do testemunho e dos factos experimentais em laboratório. Foi deste questionamento que nasceu o volume $A$ social history of truth, obra cuja recepção crítica levaria Shapin (1994) a responder em sua defesa (Feingold, 1996a, 1996b; Shapin, 1996).

Após a publicação de $A$ revolução científica, editou, em parceria com o historiador Christopher Lawrence (1998), um conjunto de ensaios históricos sobre as principais figuras dessa "revolução", apresentando-as num desfile nada convencional para quem se habituou a olhar para os cientistas como puros ascetas intelectuais. Shapin e Lawrence propõem aqui, uma vez mais usando de uma reflexividade histórica, que os produtos do intelecto fazem parte dos corpos humanos, das paixões, dos modos de vida, da humanidade mais quotidiana e material dos actores. Shapin continua a pôr em questão as imagens tradicionais e familiares da ciência. Em A revolução científica, contudo, Shapin previne para que não confundamos o trabalho sociológico que apresenta a ciência como "produto contingente, diversificado e por vezes problemático de pessoas historicamente situadas que têm interesses e preocupações morais", com uma depreciação moral da ciência - que permanece justamente a instituição de produção de conhecimento que "goza de mais credibilidade entre nós" (pp. 170-1). É uma prevenção importante. "Algo está a ser criticado", afirma, "mas não é a ciência: são certas histórias sobre a ciência, bem difundidas, que é frequente ouvirmos contar." Afinal, ao terminar a sua narrativa, o desafio para a desmistificação de certas "fábulas" históricas da ciência é devolvido ao leitor. O assalto crítico de Shapin às tradicionais versões da ciência nunca terá sucesso se não for capaz de convencer a audiência a embarcar no desafio. Talvez seja este o convite de $A$ revolução científica. 


\section{REFERÊNCIAS BIBLIOGRÁFICAS}

Barnes, Barry e Shapin, Steven (orgs.)

1979

Bloor, David

1983

Bloor, David

1976

Collins, H. M.

1983

Douglas, Mary

1978

Douglas, Mary 1970

Feingold, Mordechai $1996 \mathrm{a}$

Feingold, Mordechai 1996b

Kuhn, Thomas S. 1970

Latour, Bruno

1995

Latour, Bruno

1991

Law, John e Hassard, John (orgs.)

1999

Lawrence, Christopher

e Shapin, Steven (orgs.) 1998

Mackenzie, Donald 1981

Merton, Robert K. 1973

Merton, Robert K. 1970

Pinch, Trevor J. e Bijker, Wiebe E. 1984

Shapin, Steven 1996

Shapin, Steven 1994

Shapin, Steven 1993
Natural order: historical studies of scientific culture.

Londres, Sage.

Wittgenstein: a social theory of knowledge. Londres, Macmillan.

Knowledge and social imagery. Londres, Routledge \& Kegan Paul.

'The sociology of scientific knowledge: studies of contemporary science'. Annual Review of Sociology, 9, pp. 265-85.

Purity and danger: an analysis of concepts of pollution and taboo. Londres, Routledge \& Kegan Paul.

Natural symbols: explorations in cosmology.

Londres, Barrie \& Rockliff, Cresset Press.

'When facts matter'

(recensão a S. Shapin, A social history of truth). Isis, 87, pp. 131-9.

'Reply to S. Shapin'.

Isis, 87, 4, pp. 684-7.

The structure of scientific revolutions.

$2^{2}$ ed., Chicago, University of Chicago Press.

La science en action: introduction à la sociologie des sciences. Paris, Folio.

Nous n'avons jamais été modernes: essai d'anthropologie simétrique. Paris, La Découverte.

Actor-network theory and after.

Londres, Blackwell, The Sociological Review Monographs.

Science incarnate: historical embodiments of natural knowledge.

Chicago, University of Chicago Press.

Statistics in Britain, 1865-1930: the social construction of scientific knowledge. Edimburgo, Edinburgh University Press.

Sociology of science: theoretical and empirical investigations. Chicago, University of Chicago Press.

Science, technology and society in seventeenth-century England. Nova York, Free Press.

'The social construction of facts and artefacts: or how the sociology of science and the sociology of technology might benefit each other'.

Social Studies of Science, 14, 3, pp. 399-443.

'Letter to the Editor'.

Isis, 87, 4, pp. 681-4.

A social history of truth: civility and science in seventeenth-century England. Chicago, University of Chicago Press.

'Personal development and intellectual biography: the case of Robert Boyle'. British Journal for the History of Science, 26, pp. 335-45. 
Shapin, Steven

Shapin, Steven 1990

Shapin, Steven 1988

Shapin, Steven 1988

Shapin, Steven 1985

Shapin, Steven e

Schaffer, Simon 1985

Shapin, Steven 1981

Shapin, Steven 1979

Shapin, Steven e Barnes, Barry 1977

Shapin, Steven 1975

Shapin, Steven 1974

Shapin, Steven e Thackray, A. 1974
'Discipline and bounding: the history and sociology of science as seen through the externalism-internalism debate'. History of Science, vol. 30, pp. 334-69.

'A scholar and a gentleman: the problematic identity of the scientific practitioner in early modern England'. History of Science, vol. 22, pp. 279-327.

'The mind is its own place: science and solitude in seventeenth-century England'. Science in Context, 4, 1, pp. 191-218.

'Understanding the Merton thesis'.

Isis, 79, pp. 594-605.

'The house of experiment in seventeenth-century England'.

Isis, 79, pp. 373-404.

'History of science and its sociological reconstruction'.

History of Science, 20, pp. 157-211.

Leviathan and the air-pump: Hobbes, Boyle, and the experimental life Princeton, Princeton University Press.

'Of gods and kings: natural philosophy and politics in the Leibniz-Clarke disputes'. Isis, 72, pp. 187-215.

'Homo phrenologicus: anthropological perspectives on an historical problem'. Em Barry Barnes e Steven Shapin (orgs.), Natural order: bistorical studies of scientific culture. Londres, Sage, pp. 41-73.

'Science, nature and control: interpreting mechanics' institutes'.

Social Studies of Science, 7, pp. 31-74.

'Phrenological knowledge and the social structure of early nineteenth-century Edinburgh'. Annals of Science, 32, pp. 219-43.

'The audience for science in eighteenth-century Edinburgh'.

History of Science, XII, pp. 95-121.

'Prosoprography as a research tool in the history of science: the British Scientific Community 1700-1900'. History of Science, XII, pp. 1-28. 